Artículos Resultado de la Investigación

\title{
Aportaciones desde una perspectiva socio-jurídica al debate del trabajo sexual femenino en Colombia
}

\section{Contributions from a socio-legal perspective to the discussion of female sex workers in Colombia}

\author{
Carlos Alfonso Laverde Rodríguez ${ }^{1}$ \\ ${ }^{1}$ Universidad Santo Tomas, Colombia
}

\section{Resumen}

Se expone desde una perspectiva de género las implicaciones jurídicas que para las mujeres trabajadoras sexuales, tienen modelos reglamentarios que imponen formas de violencia simbólica, naturalizando una visión androcéntrica que define sus prácticas y discursos. Desde este marco conceptual se expone el contexto jurídico del trabajo sexual a nivel nacional e internacional.

Palabras clave: Trabajo sexual, marco jurídico, violencia simbólica, perspectiva de género

\begin{abstract}
Legal implications of regulatory models that impose forms of symbolic violence for the sexual worker women are exhibited from a gender perspective, naturalizing a male centered vision that defines its practices and speeches. From this conceptual frame the legal context of the sexual work is exhibited at national and international level.
\end{abstract}

Key words: Sex work, legal framework, symbolic violence, gender perspective

\begin{abstract}
Resumo
É exposta a partir de uma perspectiva de gênero as implicações legais para os trabalhadores do sexo feminino, tem modelos de regulação que impõem formas de violência simbólica, naturalizantes uma visão androcêntrica que define suas práticas e discursos. A partir deste marco conceitual, o contexto legal do trabalho sexual está exposta a nível nacional e internacional.
\end{abstract}

Palavras-chave: trabalho sexual, violência legal, simbólico, de gênero

Correspondencia: Carlos Alfonso Laverde Rodríguez. Universidad Santo Tomas. smials1@gmail.com 


\section{Introducción}

El comercio sexual como fenómeno histórico ha jugado su permanencia en el orden social dentro los límites de lo permitido y lo prohibido, sancionado desde discursos principalmente jurídicos, los cuales traducen la construcción social alrededor del uso del cuerpo, especialmente femenino, en ordenamientos que legitiman o no la prestación de servicios sexuales remunerados.

La aparición de la prostitución en los marcos normativos no es novedoso, sin embargo en la historia contemporánea toma un especial significado como respuesta a fenómenos globales tanto económicos como sociales que reordenan las características del trabajo sexual, ampliamente debatido por diversos sectores de la sociedad que se disputan el control discursivo que se plasma tanto en un marco jurídico como en su implementación en políticas públicas para la población involucrada.

En el caso colombiano, la sentencia T-629 de 2010 de la Corte Constitucional Colombiana, aparece como un nuevo eje de discusión que llama a contemplar la necesidad de abordar el trabajo sexual como un trabajo, obligando a las instituciones a una revisión y construcción de su política pública que garantice los derechos económicos, sociales y culturales de esta población, además de establecer garantías que permitan a las personas su libre decisión.

Dicha sentencia resalta no solo el papel institucional que debe dar cuenta de las condiciones laborales, sino que además sostiene la importancia de reconstruir los imaginarios sociales que han hecho posible que esta actividad sea históricamente juzgada a partir de connotaciones moralistas. La Sentencia insta a favorecer los supuestos de autonomía, libertad y dignidad enmarcados en los derechos fundamentales constitucionales y de los derechos humanos.

Este cambio en el discurso jurídico, pasa de un orden excluyente de la misma norma a un reconocimiento explícito, panorama que requiere miradas que aborden desde diversos ámbitos su estudio, sin dejar de lado la voz de la población.

Como resultado de la aplicación de un ordenamiento jurídico, son especialmente las mujeres ${ }^{1}$ que se dedican a esta actividad quienes pueden ser la voz del impacto de las medidas tomadas, expresados en sus estrategias que se construyen en la cotidianidad a partir de las relaciones de fuerza que ejerce el campo jurídico (Bourdieu, 2000) sobre las implicaciones sociales y laborales.

El presente artículo intenta exponer algunas dimensiones del debate conceptual, defendiendo la necesidad de una perspectiva que permita el libre desarrollo de la prestación de servicios sexuales remunerados siempre que sean de una manera libre y no coaccionada.

En el primer apartado se argumenta desde una perspectiva de género las implicaciones del trabajo sexual y las dimensiones, especialmente jurídicas, que implican un escenario de reconocimiento o negación de derechos fundamentales a quienes deciden libremente ejercer este trabajo.

En la segunda parte del artículo, se expone la perspectiva teórica para la comprensión de las estrategias y prácticas de las mujeres trabajadoras sexuales, como una respuesta al marco jurídico que define sus acciones ya sean desde una posición legal o ilegal.

Posterior al contexto conceptual, en la tercera parte se dimensiona el ordenamiento jurídico a nivel internacional y nacional, en un momento histórico en el que se discuten a el ámbito jurídico del país fenómenos como la trata de personas con fines de explotación sexual y la implementación de leyes ${ }^{2}$ que favorezcan la protección de los derechos de las personas que se dedican de manera voluntaria al ejercicio de la prostitución.

\footnotetext{
${ }^{1}$ En este estudio se toma como población de referencia solamente a mujeres, que según la SDIS (2012) son cerca del $90 \%$ de la población trabajadora sexual, aunque es importante reconocer que existe trabajo sexual ejercido por hombres.

${ }^{2}$ Actualmente cursa en el Senado de la Republica el proyecto de ley ordinaria, "Por la cual se establece un trato digno a las personas que ejercen la prostitución, se fijan medidas afirmativas a su favor y se dictan otras disposiciones orientadas a restablecer sus derechos". El proyecto es presentado por el senador Armando Benedetti
}

\section{El doble peso de la dominación: mujer y trabajadora sexual}

Las mujeres que ejercen el trabajo sexual tienen ciertas particularidades como agentes sociales en un contexto que las vulnera por lo menos 
desde dos perspectivas. En primer lugar, por el peso del androcentrismo que pone en situación de desventaja a las mujeres y en segundo lugar por cuenta de la estigmatización asociado al uso que hacen de su cuerpo.

Es así, que la construcción simbólica de los géneros y su visión androcéntrica define las dinámicas propias del trabajo sexual, comprendiendo la categoría de género como un elemento constitutivo de las relaciones sociales basadas en las diferencias que distinguen los sexos (Scott, 2000).

Desde la perspectiva de Bourdieu (2000), en su obra la Dominación masculina, la construcción sobre la que se basa el androcentrismo, se cimienta en la naturalización de lo que se ha construido socialmente, lo que ha sido denominado como el proceso de "naturalizar" la historia. La institución del proceso de naturalización de lo social ha legitimado una asimetría en las relaciones de género en el que las mujeres han contado con el peso de la dominación, en una persistencia histórica sostenida por las instituciones fundamentales de la sociedad como la religión, la escuela y la familia.

Estas instituciones han definido mediante procesos históricos la reproducción una y otra vez de los valores androcéntricos, perpetuando los patrones masculinos predominantes bajo el velo de un proceso natural que lo eterniza en una condición de invariabilidad, pues la condición que fundamenta la dominación masculina es el olvido permanente de su origen social.

Por otra parte, los roles asignados a las mujeres según Tirado (2010), han sostenido la idea de un deber ser en un contexto de moralidad instaurado por doctrinas como la católica que dio a la idea de lo sagrado en no tocar, en no pensar, en no hacer.

Es así, como en el plano de la sexualidad, la restricción, especialmente de la sexualidad femenina es controlada mediante diversos dispositivos que demarcan los espacios y acciones de lo permitido y restringido, siendo en este caso la prostitución femenina la consolidación de la trasgresión del control y expresión corporal, sancionado con estrategias de coacción social como el estigma que señala y diferencia el universo de lo bien visto. En otras palabras, la concepción social que ha naturalizado la dominación masculina, instaura esquemas de pensamiento de aplicación universal que otorgan un sentido de natural a la diferenciación simbólica del género, afirmando de manera clara lo permitido y lo prohibido.

Esta división en las sociedades modernas se oficializa con discursos como el legal, que no es refutado en la medida en que tiene que ver más con la "lógica" del funcionamiento de la sociedad, de su orden, más que con controles que requieran de fuerza explicita ya que como lo afirma Bourdieu "la fuerza del orden masculino se descubre en el hecho de que prescinde de cualquier justificación: la visión androcéntrica se impone como neutra y no siente la necesidad de enunciarse en unos discursos capaces de legitimarla"(2000, p.22).

La visión androcéntrica, se presenta como un constante reconocimiento y reproducción de sistemas cognitivos que son impuestos, dando origen a la sumisión que se basa en el oscurecimiento o degradación de los órganos sexuales femeninos, por lo que el trabajo sexual será sancionado por sacar de los recovecos de la mirada social el uso de la corporalidad femenina, en especial los órganos sexuales femeninos para prestar servicios sexuales remunerados.

Desde esta perspectiva, según Tirado:

“(...) el que la vagina siga siendo un fetiche y se le trate como algo sagrado, secreto y tabú, es una razón de que el sexo permanezca estigmatizado, tanto en la conciencia común como en la letra del derecho, pues ambas excluyen que las mujeres puedan entregarse a la prostitución como si fuera un trabajo." (Tirado, 2008 pp.30).

De esta forma, la venta de servicios sexuales remunerados ha estado fuera de los intercambios relacionados con el dinero como forma de cambio, más si se trata de las mujeres, pues se pone en el plano de lo público la sexualidad femenina que ha estado controlada en el plano de lo íntimo/privado.

Sí se tiene en cuenta, la dominación masculina sobre las mujeres y sobre el uso de su sexualidad, las trabajadoras sexuales cargan doblemente con el peso de la dominación y su sanción a la transgresión. En primer lugar por su condición de mujer y en segundo lugar por hacer uso explícito de su cuerpo en el mercado sexual.

La transgresión del uso de la sexualidad 
femenina como oferta en el mercado sexual a cambio de dinero contrapone la concepción del uso del cuerpo desde la visión androcéntrica, pues como lo menciona Bourdieu (2000), el cuerpo solo puede ser ofrecido en un acto de ofrenda exclusivamente gratuito.

Retomando, el androcentrismo se legitima mediante la inscripción a la naturaleza biológica, (siendo el pene símbolo de poder y la vagina la carencia de pene o carencia de poder). Para que esta inscripción sea sostenida es necesario de la fuerza de las instituciones.

Bourdieu (2000), poniendo un ejemplo sobre los rituales en la Cabilia, expone cómo por una parte se desfeminiza al hombre, y cómo por otra, a la mujer se le minimiza convirtiendo esta condición en virtud: mirada al suelo, piernas cerradas, paso lento, cabello largo, por citar algunos ejemplos.

La diferenciación de género se marca en la importancia atribuida socialmente a las labores. En un proceso de legitimación del androcentrismo, se atribuye una valoración de importancia a las labores masculinas en contraposición a las femeninas que se desvaloran, como el comportamiento caballeresco que no permite la realización de tareas "difíciles" a las mujeres, que se traduce en una restricción de las posibilidades de lo femenino.

La dominación por parte de lo masculino sobre lo femenino o de la relación dominador - dominado, establece tal fuerza que los dominados interiorizan y caracterizan el mundo de los dominantes, naturalizando la dominación, en este caso la femenina, "Los dominados aplican a las relaciones de dominación unas categorías construidas desde el punto de vista de los dominadores haciéndolas aparecer de ese modo como naturales" (Bourdieu, 2000, p.54).

De acuerdo a lo anterior, la aceptación relativamente inconsciente del sometimiento no se debe pues a un acto de voluntad de sumisión sino que según Bourdieu (2000), responde a un sistema de estructuras establemente inscritas en las cosas y en los cuerpos.

Al realizarse esta división de sexos, la mujer se convierte en objeto en las relaciones de producción y reproducción del capital simbólico cuyo dispositivo central es el mercado matrimonial, legítimamente construido bajo un proceso de eufemización.
Los intercambios simbólicos presentes en el mercado matrimonial, normalizan las relaciones sociales, caso contrario del trabajo sexual en el que el intercambio se realiza de forma directa, banal o mundana. La prestación de un servicio sexual remunerado excluye los eufemismos de la entrega "gratuita" en el matrimonio, pone precio y elimina el ritual simbólico de entrega.

Sin embargo, el control corporal realizado a las mujeres trabajadoras sexuales sigue en la dimensión androcéntrica, bajo la imagen de la voluptuosidad. En este escenario de trabajo se supone una vía libre a las manifestaciones corporales que desde la visión de la castidad debe ocultarse, sublimando una imagen ideal del cuerpo femenino, al que se accede mediante un intercambio explícito.

Es así, como las trabajadoras sexuales quiebran con la imagen ideal de la mujer y su uso corporal, que implica un costo social expresado en la estigmatización. Por otra parte, las mujeres que ejercen este trabajo continúan bajo la dominación masculina, esta vez por la imagen construida socialmente de la voluptuosidad femenina.

El proceso social de la trabajadora sexual, la excluye por faltar al control corporal y los mandatos de género, aunque es concebida y deseada desde el imaginario corporal femenino, proceso que explica porque en algunos modelos reglamentarios el trabajo sexual es concebido como "un mal necesario".

\section{Violencia simbólica: Estrategias eficientes de control y dominación}

La prestación de servicios sexuales remunerados crea un espacio de prácticas y discursos que lo hace único, con sus propias reglas y dinámicas que atraviesan el mundo "oculto" de la sexualidad.

En este espacio se crean dinámicas que incorporan una concepción del percibir a la mujer y al hombre, en un juego de ilusión que permite la transgresión de los mandatos de género, por lo menos en lo que a la sexualidad se refiere. Pero en este contexto de subordinación que se presenta a la mujer, ¿Por qué existe una dominación que no requiere de formas necesariamente explicitas de violencia? ${ }^{1}$, ¿Por qué la mujer estigmatizada por el trabajo sexual acepta esta condición? 
Frente a esta forma de dominación, la violencia simbólica representa la estrategia de quien domina, siendo como lo menciona Bourdieu “(...) el modo de dominación más económico porque más se adecua a la economía del sistema" (1991), por lo que no se hace necesario de mecanismos que hagan explicita la violencia.

En el trabajo sexual los controles que permiten la explotación laboral, en gran parte se constituyen por esta violencia simbólica que ordena el mundo social desde el punto de vista del dominador. La visión y organización del mundo social androcéntrico, permite controlar a las mujeres por medio de la estigmatización que es interiorizada, logrando un efecto de culpa constante por realizar un trabajo que transgrede la visión tradicional de la "buena" mujer.

La violencia simbólica hacia las mujeres trabajadoras sexuales es legitimada por los sistemas institucionales que ponen dentro de sus estrategias la naturalización del comportamiento social de la mujer en mecanismos como el Derecho, privilegiando una visión del mundo en el que la trabajadora sexual históricamente ha sido culpable o víctima de un delito, pocas veces agente de sus decisiones.

La visión del Derecho sobre las trabajadoras sexuales es una violencia simbólica que se cimienta de una forma suave, casi imperceptible, dada como algo natural y respaldada por la moral y el honor que representa la imagen de la mujer, más cuando el Derecho es un espacio privilegiado de poder creando un efecto de realidad.

En este sentido se ha pretendido sostener la idea de la teoría pura del Derecho, en un esfuerzo por construir un cuerpo de doctrinas independientes de las construcciones y presiones sociales en un intento de naturalizar la estructura normativa que revisten los marcos jurídicos.

En términos de Bourdieu "la existencia de un universo social relativamente independiente de las demandas externas al interior del cual se produce y se ejerce la autoridad jurídica, forma por excelencia de la violencia simbólica legítima, cuyo monopolio corresponde al Estado (...)" (Bourdieu \& Teuner, 2000, p. 158).

La violencia simbólica, se impone con mayor fuerza como única forma de ejercer la dominación en tanto es más reprobada la explotación directa. Es así, como la violencia simbólica latente en el trabajo sexual se difumina hasta que es aceptada por las mujeres que ejercen este trabajo, llegando a al punto de aceptación de una culpa por faltar a los principios morales, siendo así esta forma de violencia la que resulta más eficiente para los dominadores.

Retomando, para que la violencia simbólica tenga efectos perdurables sobre el control de los dominados se requiere de la institucionalización, que en el caso del trabajo sexual se hace mediante instituciones como la religión, la familia, pero específicamente desde el Estado por medio de la legislación, demarcando lo legal/legítimo de lo ilegal/ilegitimo, además de consagrar simbólicamente una situación que eterniza y universaliza la relación de fuerzas entre dominantes y dominados.

\footnotetext{
${ }^{1}$ En el comercio sexual existen formas de violencia explícita como la trata de personas con fines de explotación sexual, sin embargo, en el caso del trabajo sexual la mujer ofrece un servicio sexual de manera consciente y voluntaria, sin mediar como condición la violencia explícita
}

\section{Incorporación y reproducción: El trabajo sexual en la vida de las mujeres que lo ejercen}

El sistema mediante el cual los agentes incluyen un marco de sentido incorporando las disposiciones y formas de captar el mundo social en el que se sitúan, es denominado por Bourdieu (1991) como habitus. Permite a los agentes la aprehensión del mundo social mediante disposiciones perceptivas que son ajustadas a su posición.

Desde la mirada de quienes ejercen el trabajo sexual, se puede hacer uso del concepto de habitus, siendo este una herramienta que aporta a la comprensión de su mundo social. A pesar que las trabajadoras sexuales están en desventaja respecto a las estructuras dominantes, los esquemas de percepción atribuidos dentro del habitus, hacen evidente y natural la dominación, como se ha expuesto, por medio la de violencia simbólica dando cuenta de sus prácticas y discursos.

En este contexto, el concepto desarrollado por Pierre Bourdieu de habitus, es entendido como: “(...) ese principio generador y unificador que retraduce las características intrínsecas y relacionales de una posición en un estilo de vida unitario, es decir un conjunto unitario de elección de personas, de bienes y de prácticas." (1997, 
p.19).

Lo anterior, permite abrir nociones que esclarecen la lógica del funcionamiento de este espacio social determinado y caracterizado por unos rasgos y prácticas diferenciadoras. Así mismo, el habitus, establece los límites con lo considerado bueno o malo, que en el caso del trabajo sexual se juega entre un discurso moralista que lo juzga, y unos efectos prácticos como el dinero recibido que lo impulsa.

Las condiciones del espacio social y la configuración de un campo específico en el que se mueve la realidad de las trabajadoras sexuales, define una clase particular de condiciones de existencia, diferenciado en el caso del trabajo sexual por límites que tocan generalmente el uso del cuerpo y las construcciones significantes que de este punto se derivan, creando estructuras definitorias y generadoras de prácticas.

Las prácticas y discursos que se enmarcan dentro la producción del habitus incorporado en el trabajo sexual, se presentan no como prácticas objetivamente calculadas y racionalmente dispuestas, como lo supone el individualismo metodológico, sino que por el contrario, existen condiciones ambientadas, desde lo que llama Bourdieu (2009) estructuras estructuradas, las cuales intervienen en la sedimentación generadora de prácticas, sin que esto implique necesariamente que hayan intereses calculados en el orden establecido de estas estructuras estructurantes.

El habitus, permite incorporar para la comprensión del trabajo sexual y para quienes lo ejercen, las estructuras cognitivas construidas en un espacio que mezcla los conceptos tradicionales de género, castigando a las mujeres que ofrecen y dejando de lado a los hombres que demandan.

El habitus, como interiorización de la exterioridad, hace posible la producción libre tanto de los pensamientos como de las acciones generadas a partir de las condiciones y limites inherentes a su producción. Así mismo, el habitus es una fuente generadora de acciones impredecibles, aunque con un sentido otorgado por los límites que lo han estructurado, dando el sentido de "común", "lógico", y/o "natural" a cierto tipo de acciones que solo pueden ser concebidas de esta forma desde sus propias condiciones de producción, como la violencia simbólica de la cual son objeto las mujeres trabajadoras sexuales, asumiendo como "natural" y "lógica" la discriminación y la negación de sus derechos laborales y sociales.

De la misma forma, el habitus impulsa conductas, acciones y discursos diferenciadores enmarcados en el campo al que se refiere, dando el sentido a su producción.

Así en el campo del trabajo sexual, y solo en este campo, tiene un efecto con sentido los múltiples códigos interpretativos que se oponen precisamente a los actos con sentido de otros espacios demarcado por la conducta moral del espacio público. Por ejemplo, cuando se observa la concepción del erotismo y las prácticas sexuales, es evidente una diferenciación que define reglas que son comprendidas dentro de este espacio como formas de hablar, de moverse o de vestir, por solo mencionar algunas distinciones.

Ahora bien, pero el habitus como estructura estructurante que es incorporada al individuo, tiene múltiples dimensiones en tanto los agentes transitan por diferentes campos, entonces, ¿Cómo diferenciar las construcciones simbólicas previas y la incorporación en un mundo social en el que existen fuerzas diferenciadoras por parte de las mujeres que ejercen este trabajo?

Dentro de la conceptualización del habitus, Bourdieu hace una derivación que es de atención para la investigación, especialmente para ambientes que no son generadores de prácticas y disposiciones desde un proceso primario como lo implica la socialización en la familia, pero que si comparten introyecciones y sedimentación de las estructuras estructurantes posteriores, que hacen posible el encuentro de una construcción colectiva de un habitus común, en el que se recrean nuevas disposiciones y prácticas cercadas por un nuevo marco estructurador. Bourdieu se refiere a esto, como habitus de clase o de grupo, que en sus términos es:

"un sistema subjetivo pero no individual de estructuras interiorizadas, esquemas conocidos de percepción, de concepción y de acción, que constituyen la condición de toda objetivación y de toda apercepción, y fundar la concertación objetiva de las prácticas y la unicidad de la visión del mundo en la impersonabilidad y la sustituibilidad perfectas de las prácticas y de las visiones singulares." (2009, p.98)

El habitus de clase o de grupo se constituye a 
partir de condiciones que hacen posible la relación de esquemas previos de percepción, que pueden derivarse en el trabajo sexual en los condicionamientos y formas de relación presentes en la sexualidad especialmente la femenina que crea estructuras a partir de las cuales se conciben los límites y transgresiones, con su respectiva carga moral que podría traducirse tanto en dominación o en el desafío y sus consecuencias al orden que las posicionó (especialmente el uso y concepción de sus cuerpos).

Las mujeres que ejercen su trabajo en un campo especifico como el de la prestación de servicios sexuales, comparten eventualmente nuevas incorporaciones dentro de sus esquemas perceptivos y a-perceptivos, sin que se haga necesariamente de una forma consiente y racionalizada. Sin embargo, en este campo, la particularidad surge con una construcción del cuerpo que se construye simbólicamente a partir de la visión que se tiene de la mujer como fuente de deseo sexual. La incorporación de nuevas disposiciones de quien entra al trabajo sexual, irrumpe en una construcción previa de la sexualidad, pero se constituyen unas nuevas disposiciones frente al trabajo, incorporándose una lógica de mercado atravesada por el contexto.

Las disposiciones previas antes de llegar al campo del trabajo sexual, se transforman en disposiciones específicas, siendo para esto necesario ajustes, así sean infinitesimales para "estar a la altura" o "bajar el listón" (Bourdieu, 1999) en el caso de las prácticas en el orden de lo sexual que irrumpen en una construcción social sobre la corporalidad y sexualidad femenina, cimentadas sobre una estructura androcéntrica.

Por una parte, los clientes que conciben de una forma particular el cuerpo femenino, se otorgan libertades que en otros espacios le son negados y las mujeres por su parte, ofrecen en este solo espacio la fantasía de un acceso inmediato a la sexualidad en un juego transgresor de la tradicional concepción del cuerpo de la mujer.

En este punto se cruzan espacios que no solo conducen a la construcción de la subjetividad de las mujeres como entes aislados, sino que remite a una construcción objetiva que estructura las condiciones de producción de la subjetividad, en tanto producto de las relaciones que surgen en el mundo de lo social.
De esta forma, hablar de habitus implica necesariamente hablar de campo. Siendo la forma en la que se articula y se difumina la falsa antinomia entre objetivismo y subjetivismo, en tanto la sociedad no consiste en individuos aislados.

Tal como lo afirma Bourdieu, la sociedad “(...) expresa la suma de la conexiones y relaciones en que los individuos se encuentran" (2012, p.41), siendo tanto el campo y el habitus, un conjunto de relaciones históricas que se encuentran ancladas. En el caso del campo, en un sistema de posiciones orientadas por el poder (de control de los capitales en disputa), y en el habitus en los cuerpos por medio de esquemas mentales y corporales de percepción, apreciación y acción.

El campo como estructura objetiva, define un espacio de creación de estrategias que pueden estar objetivamente conformes con los intereses objetivos de los agentes, aunque no hayan sido concebidos como fin específico. De esta forma, los agentes en relación con el campo desarrollan esquemas generadores de estrategias.

Dentro del campo pueden surgir mecanismos de control que reproducen la violencia simbólica, suavizada y naturalizada, como se ha expuesto, por medio de mecanismo como las leyes que formalizan dando un estatus de lógico el orden social. Sin embargo, esto no bloquea una respuesta de las mujeres ante cambios estructurales que se traducen en estrategias adaptadas al habitus de grupo.

Las preguntas que se plantean en esta investigación surgen alrededor de la relación que se establece entre el campo jurídico, como fuente visible de un ordenamiento que estructura y define el habitus de clase o grupo, que las mujeres trabajadora sexuales adoptan no como una fuente visible y objetiva de ordenamiento sino como una fuente que legitima o no, criminaliza o permite sus acciones.

El impacto del marco jurídico, puede ser variado de acuerdo a los sistemas jurídicos y sus percepciones respecto al trabajo sexual. No es lo mismo hablar de marcos jurídicos prohibicionistas que castigan a la mujer 0 al cliente, a otros reglamentarios o legalistas que hacen explícitos derechos laborales y sociales a las mujeres.

De esta forma el marco jurídico que estructura y define las estrategias de las mujeres que ejercen 
el trabajo sexual, es una representación de las disputas dentro del campo jurídico, el cual intenta mediante la racionalización desvanecer las intuiciones ingenuas de la equidad (Bourdieu \& Teubner, 2000) a favor de un sistema objetivo, que se impone sobre aquellos que lo padecen dando un apariencia de independencia de las relaciones de fuerza que están en disputa.

Así la relación entre campo y habitus, es un espacio de construcciones históricas que dan el sentido al juego por medio de conflictos y competencia que configuran las relaciones objetivas entre las posiciones.

En otras palabras, el campo es el espacio en el que se encuentran inmersas las construcciones históricas que dan sentido al juego y articulación del habitus, siendo como lo afirma Bourdieu (2012), un espacio de conflicto y competencia que configuran relaciones objetivas entre posiciones:

"Estas posiciones están objetivamente definidas, en su existencia y en las determinaciones que imponen sobre sus ocupantes, agentes o instituciones, por su situación presente y potencial (situs) en la estructura de distribución de especies del poder (o capital) cuya posesión ordena el acceso a ventajas específicas que están en juego en el campo, así como por su relación objetiva con otras posiciones (dominación, subordinación, homología, etcétera)."(2012, p. 135)

El campo ordena y clasifica las posiciones aunque no de una forma inmutable, a su vez define e incorpora al esquema perceptivo de quien está inmerso, explicando las disposiciones y esquemas que generan y organizan prácticas y representaciones de los agentes.

Así, en el caso colombiano, antes de la Constitución de 1991, en donde se garantizan las libertades individuales en el marco de un Estado de Derecho, predomina en el caso del trabajo sexual un marco prohibicionista, que si bien expone el accionar de las instituciones estatales (como la represión en el caso de la policía), es interiorizado por las mujeres que se arriesgan a detenciones y violaciones de sus derechos, siendo naturalizada la violencia en la medida en que se reconoce el atentado al orden social.

El orden social que castiga y criminaliza el uso de cuerpo con fines comerciales, no solo señala y castiga, sino que además se incorpora y legitima dentro del mismo habitus de las trabajadoras sexuales. Por medio de la violencia simbólica que requiere de la complicidad del dominado, en este caso de las mujeres perseguidas que perciben como "normal" la represión, pues comprenden su conducta como inapropiada.

Las mujeres sexoservidoras que comprenden y aceptan la represión en un marco jurídico prohibicionista, sincronizan la concepción instaurada desde el campo respecto a sus prácticas y sus definiciones sobre lo permitido y lo prohibido, legitimando por una parte la sanción y por otra incorporándose dentro de un segmento transgresor a la moral, es decir, la mujer se autocensura con las herramientas mismas que ofrece el campo jurídico.

Sin embargo, el campo, en este caso el jurídico, no es inmutable dándose espacio de luchas y conflictos entre actores. De acuerdo a Amparán (1998) el campo se construye como un espacio en el que tiene lugar un conflicto entre actores, los cuales se disputan un capital especifico que tiene un valor igualmente compartido por quienes lo disputan, a pesar que su apropiación no se encuentre simétricamente dispuesto por las relaciones históricas que sitúa a los actores en posiciones diferenciadas frente al capital del campo.

Si se observa la lucha jurídica por el reconocimiento de los derechos de las mujeres trabajadoras sexuales, se podrá distinguir unas diferencias lo suficientemente asimétricas, que contiene luchas a su vez por el reconocimiento de la desigualdad de género, aunque esto no significa un campo libre de disputas.

Es claro que desde los años setenta se comienzan las luchas de las primeras asociaciones en defensa de los derechos de las mujeres trabajadoras sexuales que hoy se extiende por todo el mundo.

Actualmente las agendas legislativas se transforman e incluyen discursos que permean el mismo uso del lenguaje, reconociendo la actividad y vulneración a la que están expuestas las mujeres dedicadas a este oficio, ya sea desde el plano más prohibicionista que gira sus ojos al cliente (Suecia) o centra su atención en el reconocimiento de los derechos laborales (Alemania).

Por otra parte, si bien existen capitales en disputa, no se podría definir la posición explicita 
de los agentes. En el comercio sexual las dimensiones que se entretejen son múltiples porque su categorización así lo es.

El comercio sexual, ofrece una gran variedad de tipologías que van desde la prostitución directa, hasta la pornografía, los video-chats, el pole-dance, entre otras categorías que además ofrece distinciones de acuerdo a la posición económica, género o condición étnica (Tirado, 2010).

El posicionamiento de los agentes, en este caso las mujeres trabajadoras sexuales resulta diverso y sus condiciones laborales sociales también. Sin embargo en el campo definido en el comercio sexual, es claro "lo que está en juego", es evidente para los agentes, la inversión realizada, o como Bourdieu lo denomina "illusio" (1999).

La inversión realizada y compartida por los agentes define lo que está en juego, es el interés compartido por lo que se juega, "Los jugadores acuerdan, por el mero hecho de jugar y no por medio de un "contrato", que el juego merece ser jugado, que vale la pena jugarlo, y esta cohesión es la base misma de su competencia." (2012, pp.136, 137).

En estos términos, La illusio dentro de un campo especifico, representa acabar con la indiferencia que pueda presentar un jugador, además de ser movido por los estímulos presentes en el campo que hacen que el jugador se comprometa en el juego.

En el campo de las relaciones de género presentes en la concepción del comercio sexual, la disputa se dan el marco de la concepción androcéntrica del uso del cuerpo de la mujer (Lamas, 2003), legitimado por cuenta de los discursos jurídicos que influyen en las condiciones sociales y laborales, en un contexto social en el que se interpretan y reinterpretan las desigualdades de género presentes en las prácticas y discursos de las mujeres trabajadoras sexuales.

\section{Trabajo sexual como alternativa válida: aproximación a discusiones aun no resueltas}

A partir del uso de la categoría trabajo sexual, se expone el ordenamiento jurídico tanto a nivel internacional como nacional, lo que permite abordar la descripción de un debate que se da en ámbitos como el académico y el legislativo, pero que finalmente repercute en las condiciones sociales y laborales de las mujeres trabajadoras sexuales.

\section{El uso del cuerpo en el trabajo sexual}

Con el paso a la moderna era industrial, en el modo de producción capitalista se reorientaron las relaciones del sujeto y el cuerpo, "el hecho de que el obrero haya tenido que desvencijar su sistema tradicional de vida, arrendar su fuerza de trabajo a un sistema que demandaba generar ganancia a través de él, debilitó las posibilidades que éste tenía para integrar todas las dimensiones de su motricidad." (Sánchez, 2011, p. 125). Instituyéndose reglas en el cuerpo, dando privilegio a la eficiencia y la capacidad productiva, instaurando como lo menciona Sánchez (2011), una identidad funcional para la motricidad del cuerpo humano.

Con la intensificación de las diversas formas de producción y reproducción del capital, el cuerpo se ha puesto en un plano central de las modernas sociedades, por lo que la sociología comienza a abrir espacios de discusión en los que se incorpora el cuerpo y sus relaciones con el poder, ampliamente señalado por pensadores como Michel Foucault $(1975,1977)$ o Pierre Bourdieu (2004, 2009, 2012).

Por otra parte, la incorporación del estudio con perspectiva de género ha permitido la inclusión del cuerpo sexuado como una centralidad en las relaciones entre feminidad y masculinidad a partir de su construcción simbólica. Como lo menciona Lamas, (2007) la existencia de los seres humanos es corporal, siendo "(...) la síntesis de un proceso biológico, una estructuración psíquica, una producción cultural y un momento histórico. Cada sociedad elabora simbólicamente su concepción del cuerpo." (p.2).

En la actualidad, el cuerpo se ha convertido como lo afirma Barreiro (2004), en la presentación y representación del "yo", ganando espacios en relación con los nuevos estilos de vida que han dado importancia al cuidado interno y externo del cuerpo, como valor de la modernidad en el retorno del mito de la eterna juventud.

Resulta pues contradictorio el afán de cuidado de la estética y de la salud, con el crecimiento de enfermedades como la bulimia, anorexia, la 
dependencia de productos para mantener la forma y los riesgos de operaciones estéticas que no siempre resultan exitosas.

Como lo menciona Barreiro (2004), el poder sobre el cuerpo no solo lo moldea sino que involucra una lógica de la dominación ejercida por los mandatos de género, que se extiende más allá de la expresión corporal a comportamientos, acciones, pensamientos y formas de actuar que corresponden con la imagen que se espera en el proceso que es visto como "natural".

Así como los mandatos de género representan una visión clasificatoria del mundo que asignan roles a hombres y mujeres, otorgan sistemas clasificatorios sobre el uso del cuerpo, reprimiendo tanto a hombres como mujeres el uso corporal de tal forma que se adecuen a los mandatos de género.

En este contexto, en la actualidad el uso del cuerpo da cuenta de la reconfiguración del mercado y de la cultura de masas que sublima el cuerpo en dos sentidos, tanto como sostén de la industria moderna como del resurgimiento del hedonismo. El cuerpo de las mujeres es el centro de atención estética, física y erótica.

Con la sublimación del cuerpo y el desarrollo de sus expresiones más íntimas expresadas en la sexualidad y el erotismo, la privación y represión se desliza por las construcciones simbólicas de la corporalidad a nuevos ámbitos como el trabajo.

El trabajo reprime el cuerpo a través de diversas expresiones, en el que las construcciones sociales de género condensan los roles de lo masculino y femenino en dicotomías que ordenan el mundo significante.

Estas dicotomías otorgan a las mujeres una sumisión a los roles "no productivos" dentro del sistema industrial, que fortalece la idea del hombre como sostén y jefe en la figura de padres y esposos.

Bajo esta perspectiva, el trabajo de las mujeres en el mercado laboral se ha subvalorado y precarizado comparado con las condiciones laborales de los hombres, bajo supuestos economicistas que privilegian la eficiencia y productividad de la especialización laboral de los hombres.

La construcción simbólica alrededor de los sexos y el trabajo han minimizado las opciones en el mercado laboral para las mujeres, relegando en muchas ocasiones su trabajo a roles del ámbito privado (secretaria, trabajadora doméstica, recepcionista, entre otros oficios).

Esta asignación socialmente construida, es controlada. La transgresión de los límites impuestos conlleva a controles sociales como el estigma, soportado en muchos casos por la legislación que regula los cuerpos.

Este es el caso del trabajo sexual, el cual si bien no es una manifestación nueva como actividad económica y social, ha tomado matices en un época histórica en la que a pesar de promulgar cierta liberación sexual, se comercializa la sexualidad y lo erótico en espacios que trasgreden y difuminan los límites de lo íntimo, al tiempo que castiga, criminaliza y estigmatiza a las mujeres que de forma voluntaria y consiente deciden realizar esta actividad como una opción laboral.

\section{El cuerpo en la prestación de servicios sexuales remunerados}

El mundo de la sexualidad se despliega creando imágenes ideales a perseguir, el cuerpo de las mujeres y hombres se convierten en objeto de deseo. En este orden, las transformaciones corporales se dirigen hacia la satisfacción de imágenes creadas en la cultura de masas.

En este contexto la comercialización del deseo, del placer, de la sexualidad y del cuerpo, otorgan al trabajo sexual visos de complejidad en los nuevos discursos de la sexualidad, abriendo el panorama a la discusión.

Desde una parte de la discusión se ha señalado que la prestación de servicios sexuales remunerados degrada y oprime a las mujeres ya que las coloca en la posición de servidumbre sexual frente a los deseos masculinos (Aucía, 2008). Desde esta perspectiva, se considera que hablar de prostitución libre y forzada es como hablar de esclavitud voluntaria e impuesta, siendo finalmente esclavitud.

Por otra parte, están quienes consideran que el trabajo sexual se puede convertir en una forma de emancipación económica al disponer del cuerpo autónomamente, pues responde a una demanda del mercado que se está dispuesta a satisfacer a cambio de una remuneración 
económica, siendo esta actividad un trabajo, pues existen las condiciones contractuales para considerarlo de esta forma.

Sin embargo, considerar el trabajo sexual como una opción laboral, plantea varias problemáticas. Como se ha expuesto, puede ser reprochable, sin embargo, es necesario cuestionar sí reprimir esta manifestación libre del cuerpo es, como lo afirma Teresita de Barbieri (1992), controlar el cuerpo de las mujeres y dirigir su trabajo para no permitir que se escape del control, "Porque podría ser que sin controlar la capacidad de trabajo, las mujeres tuvieran posibilidades de dominar la sociedad o exigir el reconocimiento de su reproducción." (p.8).

En este orden, la discriminación a la mujer que decide voluntariamente ejercer el trabajo sexual la obliga soportar un proceso de constante transgresión, entre el esconder y el mostrar, constituyendo unos rasgos distintivos de su espacio social, que en sí, es su espacio de trabajo, uno que sufre las condiciones del estigma. Como lo señala Nussbaum (1999), el estigma, puede estar basada en prejuicios o estereotipos de género, lo que explica sus altos salarios como forma de compensación.

El estigma del trabajo sexual se funda en el uso del cuerpo, pero es necesario recordar que en épocas precedentes, el estigma también estuvo presente en ocupaciones como los cantantes de ópera.

Nussbaum (1999), demuestra que el estigma sobre la prostituta es fundado en creencias irracionales, por cuenta de la dominación masculina que ejerce la violencia simbólica a través de un acto de conocimiento y de reconocimiento práctico, en una especie de poder "hipnótico", como lo señala Bourdieu (2000), que en una especie de llamamiento al orden, reprime la sexualidad de la mujer y más cuando es remunerada económicamente por el uso de su cuerpo.

Muchas de las creencias sobre el trabajo sexual, atribuyen sus motivaciones a causas como la pobreza, la falta de capacitación, sumado a las asimetrías en las relaciones de género que entregan menos posibilidades de desarrollo a las mujeres. Sin embargo, ipor qué dentro de las opciones laborales las mujeres se convierten en trabajadoras del sexo?

En un boletín emitido por un colectivo de trabajadoras sexuales, se expone:

"Dentro de un marco de derechos y poder de decisión las trabajadoras sexuales definimos nuestra actividad como un trabajo, más allá de las eternas discusiones con grupos moralistas, algunas organizaciones de mujeres que se ven estimuladas por un imperativo moral de "salvar" a mujeres inocentes (poniéndonos en el papel de víctimas y apuntándonos el derecho de hablar por nosotras mismas); así algunos programas provienen de la idea de que las mujeres necesitan ser "rescatadas y rehabilitadas", en lugar de apoyarnos y otorgarnos derechos; el término "trabajo sexual", "no expresa la explotación que supone el tráfico y la prostitución" (Asociación de trabajadoras sexuales "Miluska, V. y D, 2006, p.8)

En esta declaración, la asociación de mujeres trabajadoras sexuales "Miluska", ponen en evidencia una necesidad de reconocimiento de su trabajo, dejando en claro que realizan una actividad legítima que debe ser reconocida.

Se puede afirmar que el trabajo sexual se hace por necesidad y no por libre elección, pero es cierto que este análisis podría hacerse de igual forma para la gran diversidad de trabajos que responden a una necesidad económica como el ser oficinista, cantante, profesor/a o cualquier otra actividad, pero que finalmente se eligen. ¿Por qué se cuestiona la libertad de elección laboral de las mujeres trabajadoras sexuales?

Las posiciones que conciben el trabajo sexual como una forma de explotación a la mujer, no tienen en cuenta, como lo menciona Lamas (2003) que, “(...) olvidar la fisiología es no darle el peso debido a la "ventaja" de la receptividad de la anatomía femenina frente a la "exigencia" de la fisiología masculina" (p.241), olvidan la ventaja anatómica de las mujeres frente a los hombres, “(...) pero por la valoración cultural previa, o sea, por el género, esa ventaja "biológica" se traduce en nuestra sociedad como "desventaja" social" (Lamas, 2003, p. 274), consolidando un circulo en donde aprovechar esta ventaja biológica implica para la mujer que ejerce el trabajo sexual la estigmatización.

Desde esta perspectiva, criminalizar, prohibir o abolir el trabajo sexual no puede resultar beneficioso para quienes deciden libremente realizarlo, siendo necesario crear las condiciones que permitan salvaguardar a trabajadores/as sexuales contra el abuso y la enfermedad, 
condiciones que se pueden dar en un marco jurídico que visibilice la actividad, como lo ha hecho evidente Montoya (2012) en el caso colombiano.

Reconocer la categoría de trabajo sexual, implica no desconocer la posibilidad de agencia de las mujeres que realizan este trabajo de forma voluntaria y consiente, en contraste con otras categorías como prostituta o mujer en estado de prostitución, categorías que niegan la autodeterminación y decisión, además de reproducir el estigma a la mujer que decide sobre el uso de su propio cuerpo.

\section{Ordenamiento jurídico en el trabajo sexual: estado de la cuestión}

La dualidad de posiciones frente a la forma en la que se aborda la problemática vinculada al trabajo sexual, es un tema recurrente en los sistemas legislativos a nivel mundial, no solo desde lo que implica en el plano moral de la prestación de servicios sexuales remunerados sino además del contexto del comercio sexual que involucra dinámicas adyacentes.

Dentro de las dinámicas que se desprenden del trabajo sexual, se puede señalar el alto riesgo asociado de contraer enfermedades de transmisión sexual (ETS) tanto de los/las trabajadores/as del sexo como de los clientes por el alto número de parejas que supone la actividad (ONUSIDA, 2009).

Así mismo, fenómenos como la trata de personas con fines de explotación sexual, la explotación de niños, niñas y adolescentes (Tirado, 2010), que ha tomado dimensiones difíciles de ocultar para los Estados en este nuevo ámbito de crimen organizado y eliminación de las fronteras nacionales (Rubio, 2008).

Bajo la complejidad de realidades que se desprenden de las dinámicas del trabajo sexual surgen diversos modelos normativos que intentan dar respuesta al fenómeno, partiendo de una perspectiva que se cimienta desde la visión moral imperante en una sociedad.

\section{Modelos normativos}

Las legislaciones se han clasificado históricamente en 4 modelos normativos principalmente: prohibicionista, reglamentarista, abolicionalista y legalista.

Prohibicionista. Este modelo se fundamenta en que el trabajo sexual atenta contra los principios expuestos en los derechos humanos, por lo se deben tomar acciones legales contra quienes se dedican a esta actividad (Tirado, 2010). Este modelo contiene una visión que se podría denominar moralista que defiende la moral pública y las buenas costumbres.

En este modelo "Las personas que ejercen la prostitución están equiparadas a los delincuentes, mientras que los clientes son vistos como víctimas de la invitación escandalosa y provocativa de las prostitutas." (Secretaria Confederal para la Igualdad. Departamento Confederal de la Mujer Trabajadora UGT, 2005: p.5).

El prohibicionismo persigue a quien ofrece el servicio sexual remunerado dejando sin responsabilidad al cliente, lo que supone omitir la multi-causalidad que transita el trabajo sexual, al no reconocer las estructuras organizativas que se tejen en el marco de la ilegalidad que supone esta perspectiva normativa, asumiendo que la conducta delictiva recae exclusivamente sobre quien presta el servicio sexual.

Abolicionismo. Esta corriente jurídica supone que el trabajo sexual no puede darse de forma voluntaria, por lo que el uso del cuerpo para la prestación de servicios sexuales representa una forma de explotación por quienes manejan el negocio, lo que significa un atentado contra sus derechos humanos.

Según Daich (2012) el abolicionismo concibe que “(...) la prostitución es una institución patriarcal basada en la desigualdad entre varones y mujeres y que no puede, bajo ningún concepto, ser considerada trabajo." (p.74)

La autora (Daich, 2012) considera que pensar la sexualidad desde una visión de dominación masculina, como algo dado y definitorio, representa una visión reduccionista de las relaciones de género, avalando posturas conservadoras como la cristiana que no beneficia de ninguna manera a las mujeres.

Es así, que desde esta corriente se concibe a la mujer que ejerce el trabajo sexual como una víctima tanto del patriarcado como de la estructura del mercado, que es manejado por intereses económicos que despoja de la dignidad 
a la mujer trabajadora sexual, favoreciendo los intereses económicos del proxeneta.

Como lo menciona Rubio (2008): "es cierto que el abolicionismo parte de un conjunto de principios y valores, pero este conjunto axiológico representa la base necesaria en la que es posible ejercer en igualdad y en libertad los derechos individuales" (p. 80). El principio de libertad en el trabajo sexual queda reducido a una expresión que no puede concretarse en hechos reales, debido a que son necesarias condiciones materiales para poder tomar decisiones libremente.

Por su parte De Lora (2007) sostiene que los Estados que mantienen un modelo abolicionista, conciben la prostitución como una "actividad básicamente degradante e indigna; antes bien, debe dirigir sus esfuerzos en pos de su desaparición" (De Lora, 2007: p.457).

Sin embargo, esta posición al querer eliminar la prostitución deja en suspenso a quienes deciden de forma voluntaria ejercerla, anulando las posibles protecciones en términos de salud o de protección social que brinden los Estados (Tirado, 2010).

Esta corriente, niega la existencia de la prostitución, siendo la negación la estrategia de extinguirla, como lo afirma Nettle (2005) "Se pretende evitar el comercio sexual de personas, aboliendo toda reglamentación relativa a la prostitución, cerrando los clubs y suprimiendo inscripción de prostitución en registros policiales y sanitarios" (p.6), así como lo enmarca el "Tratado Convenio para la represión de la trata de personas y de la explotación de la prostitución ajena" firmado por la ONU en 1949, acciones que no dejan por tanto, la menor posibilidad de protección del Estado mediante marcos jurídicos a las personas que desarrollan el trabajo sexual.

El modelo abolicionista ha sido criticado desde diversos sectores como los de las asociaciones de mujeres trabajadoras del sexo y por ciertos sectores feministas debido a que supone que quien ejerce el trabajo sexual no tiene voluntad ni capacidad de decisión, además de criticar cierto carácter moralista sobre el uso que cualquier persona realiza sobre su cuerpo (Rubio, 2008).

Reglamentarismo. Desde esta corriente, se concibe la prostitución como un mal menor y necesario, por lo que reconoce su existencia con la protección en temas como la salud y el establecimiento de zonas especiales en las que se pueda controlar y vigilar el orden público.

De acuerdo a la organización en zonas delimitadas para el ejercicio del trabajo sexual, las pretensiones no son de protección a la libertad personal sino de control de un mal que puede derivar en aumento de problemas sociales como las ETS. Se establecen medidas para que quien ejerce el trabajo sexual asista periódicamente a controles sanitarios para así evitar problemas de salud pública.

El modelo reglamentarista define implícitamente una distinción entre la prostitución libre y forzada, que permite diferenciar y dimensionar problemáticas como el tráfico y la explotación sexual.

Desde corrientes feministas, este modelo es criticado debido a que la reglamentación solo favorece a los proxenetas que pueden mantener sus negocios sin restricciones como lo suponen otros modelos (Carracedo, 2006).

El argumento central de las críticas que se le hacen a este modelo es que no se puede suponer la voluntad de una mujer para ejercer la prostitución sin tener en cuenta las condiciones económicas y sociales, como lo afirma Carracedo (2006) "La voluntariedad aislada de las condiciones de vida y de las relaciones de género constituye una herramienta inútil para aprehender y comprender el fenómeno de la prostitución" (Carracedo, p. 64).

Sin embargo, adoptar el argumento de la voluntariedad como una condición determinada por las condiciones sociales, económicas y culturales (estructurales) supone eliminar de la discusión aspectos relevantes de la subjetividad propia de los agentes sociales en contextos diversos, negando así mismo la diversidad de categorías existentes en el comercio sexual.

En este sentido las discusiones sobre la autonomía que se han dado desde la filosofía política no han sido pocas. Apiah (2007) en "La ética de la identidad", expone los dilemas en los que se mueve la autonomía " (...) estamos confinados a las opciones que tenemos a nuestro alcance, las cuales, a su vez, se caracterizan por su inmovilidad sustancial: constituyen un nexo de instituciones y prácticas que nosotros no creamos."(Apiah, 2007: p.98) 
Remitir únicamente la decisión de quien ejerce el trabajo sexual a sus condiciones económicas y sociales es dejar de lado la autonomía propia de las mujeres, de quienes en el marco de diversas opciones eligen el trabajo sexual como su actividad económica.

Legalización. Esta última corriente intenta a diferencia de la reglamentación abordar los derechos laborales de quienes se dedican al trabajo sexual, no como un mal necesario o menor, sino por el contrario, se reconocen las garantías y derechos laborales como a cualquier otro trabajo.

Se busca reconocer derechos que van desde el acceso a la salud hasta el cumplimiento de un horario, el derecho a sindicalizarse, aportes para jubilación, entre otros, en el marco de la concepción laboral.

Desde este enfoque, de acuerdo como lo plantea Tirado (2010) se "combate el proxenetismo organizado y la prostitución forzada" (p.209), con el propósito de garantizar y reconocer a quien presta servicios sexuales como un sujeto de derechos.

Este modelo es especialmente defendido por las asociaciones de mujeres trabajadoras sexuales a lo largo del mundo, quienes en su agenda política buscan defender y exigir su autonomía y libre decisión, además de demandar a los Estados su reconocimiento y diferenciación con fenómenos como la trata de personas.

El modelo que busca la legalización del trabajo sexual, va en contravía del modelo abolicionista o reglamentarista, sustentado como se ha mencionado, en la libertad del individuo que es cohibida por las concepciones moralistas.

De Lora (2007), sostiene que las posiciones abolicionistas que critican los modelos legalistas se inclinan hacia "un Estado que pretende imbuir virtud a los ciudadanos tratando de que desarrollen planes de vida que (desde algún punto de vista) se considera valiosos."(De Lora, 2007: p.460), siendo el mismo Estado que ha castigado el adulterio, el aborto la pornografía y otras conductas "indeseables", con todas las implicaciones que trae en términos de las libertades individuales.

En el modelo que se encuentra a favor de la legalización se considera que los demás modelos que intentan perseguir ya sean al cliente, al proxeneta 0 a quien presta el servicio sexual, inciden en procesos que llevan a la clandestinidad de la prostitución.

En estos términos, la clandestinidad representa la oportunidad de crear las condiciones para un mayor beneficio a proxenetas y/o dueños de establecimientos. Existe un incremento en precios por cuenta de la dificultad de acceso al servicio requerido que no se traducen en beneficios para las mujeres prestadoras de servicios sexuales.

En este sentido, al igual que en otros mercados que se definen como ilegales, Becker, Murphy \& Grossman (2006) en su estudio sobre los mercados ilegales, referido al caso de las drogas, pero que se puede, según los autores, extrapolar a fenómenos como el comercio sexual, exponen que “ (...) se supone que la demanda depende del precio de mercado, el cual es afectado por el costo que se impone a los traficantes con la persecución y el castigo, como la confiscación de drogas y el encarcelamiento." (Becker, Murphy \& Grossman, 2006: p.20).

Este argumento pone de manifiesto un posible panorama de desventaja en la prohibición/abolición de la prostitución, que puede tener consecuencias negativas para la lucha, por mencionar un caso, del tráfico con fines de explotación sexual y el desmejoramiento de las condiciones laborales de un marco reglamentario/legalista en el que las entidades oficiales pueden tener algún control, causando un fenómeno de invisibilidad de quienes ejercen el trabajo sexual.

\section{Panorama internacional}

La discusión sobre modelos jurídicos, muestra en el escenario internacional una gran heterogeneidad, siendo la muestra del escaso consenso alrededor del trabajo sexual, enmarcándose en los modelos mencionados y las discusiones sobre la pertinencia o no de determinado modelo jurídico.

Aunque los modelos, a lo largo del mundo se extienden en diversidad, existen dos extremos en los que se mueve el marco jurídico. El panorama se dirige desde el plano más coercitivo, como lo puede ser el caso de Suecia que persigue al proxeneta y al cliente, o bien, Alemania, que por otra parte, intenta visibilizar el ejercicio del trabajo sexual, por medio de la garantía de los derechos laborales además de 
ofrecer alternativas de reconversión laboral.

En otros casos, dentro de un mismo país se encuentran posiciones jurídicas contrarias, como es el caso de Australia y Estados Unidos, países que se mueven en marcos reglamentarios que van desde el prohibicionismo (Territorio Capital de Australia y California) hasta la legalización (Nevada y Victoria).

En países como Inglaterra y España, se mantiene una protección de quien ejerce el trabajo sexual, sin embargo se castiga al cliente y a la persona que faciliten las condiciones para la prestación de servicios sexuales, ya sea el proxeneta o el dueño de un establecimiento en el que se dé la transacción, con penas que pueden ir hasta siete años de prisión en el caso inglés.

Respecto al modelo en Suecia (prohibicionista) se ha afirmado su éxito en el modelo jurídico ya que se evidencia una considerable disminución frente al tráfico de mujeres con fines de prostitución (Apramp/Fundación de mujeres, 2005).

Sin embargo, autores como De Lora (2007), sostiene que el modelo sueco si bien resulta exitoso, no puede afirmar que la prostitución haya sido abolida, siendo más bien la migración del escenario de la calle al interior de algún hotel, restaurante, club, nocturno, o casa particular.

En contraste, en países como Holanda y Alemania se ha adoptado un modelo legalista del trabajo sexual, ofreciendo derechos laborales como pensiones de invalidez, salario mínimo, condiciones específicas en el servicio sexual en el que pueden negarse a realizar un servicio, entre otras condiciones que supone la legislación laboral.

En un informe presentado por el Ministerio de Familia, Tercera Edad, Mujer y Juventud de Alemania, se presenta una evaluación de los efectos de la ley reguladora de la situación jurídica de las personas que ejercen la prostitución (Ministerio de Empleo y Seguridad Social, Gobierno de España, 2007), en el cual se demuestra que el efecto de la ley que rige desde el 2001 no ha sido del todo efectiva en la medida en que la estigmatización asociada al ejercicio del trabajo sexual, impide en algunos casos las demandas civiles contra los clientes, además del escaso conocimiento de la ley por parte de las trabajadoras sexuales.

De la misma forma, por cuenta de los requerimientos que implican un contrato laboral, las trabajadoras sexuales han preferido según el informe, mantenerse como trabajadoras independientes, desligándose de la subordinación que trae un contrato como el manejo de horarios y ubicaciones de trabajo, lo que pondría en riesgo el anonimato necesario que supone su trabajo.

A pesar de los inconvenientes con las formalizaciones de los contratos laborales, el estudio demuestra que la gran mayoría $(86,9 \%)$ de las trabajadoras sexuales cuentan con seguridad en salud.

Este informe, ha sido el referente de críticas al modelo alemán sobre la legalización del trabajo sexual, sin embargo, es importante señalar que el modelo no ha tenido inconvenientes por su concepción de las libertades y la concepción laboral del trabajo del sexo. La principal problemática está orientada por el señalamiento moral a quien desarrolla esta actividad, limitando el acceso ante las autoridades civiles para denunciar o validar sus contratos laborales, sumado al poco compromiso de los administradores de establecimientos en asumir la carga que implica un contrato laboral.

\section{Marco jurídico en Colombia}

En el marco de la Constitución Política de Colombia promulgada en 1991, en su Capítulo 1, articulo 13 se afirma que:

"Todas las personas nacen libres e iguales ante la ley, recibirán la misma protección y trato de las autoridades y gozarán de los mismos derechos, libertades y oportunidades sin ninguna discriminación por razones de sexo, raza, origen nacional o familiar, lengua, religión, opinión política o filosófica."

El Estado colombiano se adhiere a la protección de las libertades individuales, garantizándolas mediante la protección de los derechos sin ninguna clase de discriminación, además de promover las condiciones para que la igualdad sea real y efectiva adoptando medidas a favor de grupos discriminados y marginados.

Desde este punto de vista, el Estado colombiano no castiga el ejercicio de la prostitución, por ser una actividad que se mueve en el plano de las libertades personales, sin embargo en el Código Penal (Ley 599 de 2000) se explicitan los castigos a quien induzca a la prostitución con el 
ánimo de lucrarse o satisfacer deseos de otro (artículo 213), constreñimiento de la prostitución (artículo 214) y trata de personas (artículo 215), con penas que varían entre los dos y los nueve años de prisión.

En el marco de la Constitución Política de Colombia y de normas legales como el código penal, se establecen precedentes a partir de las cuales las entidades territoriales toman decisiones respecto a la forma de concebir la prostitución, lo que cambia las condiciones de ejercicio del trabajo sexual de una ciudad a otra.

Esta diferenciación normativa es un factor asociado a la movilidad y concentración de la actividad en ciudades como Bogotá, como lo señala la Secretaría Distrital de Integración Social (SDIS), en su informe diagnostico (2012) sobre la prostitución en la ciudad. ${ }^{1}$

A nivel nacional, el marco jurídico referente a la prostitución puede rastrearse desde la emisión de sentencias de la Corte Constitucional, que después de la Constitución de 1991, emite sentencias relacionadas con demandas de ciudadanos que se sienten vulnerados por la presencia de la actividad en zonas cercanas a su vivienda o lugar comercial (Sentencia T620 de 1995, Sentencia SU476 de 1997).

En el 2010 se instaura una acción de tutela por parte de una mujer trabajadora sexual. La mujer ingresó a laborar con un contrato verbal indefinido en un bar en el que se prestaban servicios sexuales. Esta mujer fue despedida por las circunstancias propias de su embarazo, negándose su jefe a reincorporarla de nuevo al trabajo.

La deliberación que se planteó la Corte Constitucional a lo largo de la Sentencia T-629 de 2010, fue sobre la posibilidad de afirmar la prostitución como una actividad económica por medio de la garantía de derechos y deberes laborales, en términos de Nieto (2010), la Corte se planteó "Si es jurídicamente posible, un Estado de Derecho liberal, como pretende ser Colombia, la existencia de una relación laboral entre prostituta y propietario de un local comercial." (Nieto, 2010, p.2).

La respuesta a esta pregunta, la define la Corte Constitucional al concluir que LAIS2:

“(...) desarrolló una actividad personal como trabajadora sexual y en la prestación de otros menesteres al servicio del bar PANDEMO, durante los meses de febrero de 2008 y marzo de 2009, tareas realizadas de manera continuada y sujetas a las reglas de subordinación y dependencia admisibles en cuanto a los servicios sexuales y a las demás tareas desempeñadas para la comercialización, organización y limpieza del bar, todo ello a cambio de una retribución económica.

Esto es, que se configuró un contrato realidad cuyos términos en el tiempo no están determinados con total precisión en el proceso de tutela, salvo en lo que hace a la fecha de despido, pero cuya existencia se acredita de manera suficiente para reconocer la violación de derechos fundamentales al trabajo, la seguridad social, la igualdad, la dignidad, la protección de la mujer en estado de embarazo, el derecho del que está por nacer, el fuero materno y el mínimo vital." (Sentencia T-629 de 2010: p.101)

En la sentencia, la Corte Constitucional reconoce los derechos laborales de la mujer demandante, pero además reconoce los derechos de los y las trabajadoras sexuales con fundamento en el derecho a la igualdad y dignidad.

La sentencia fundamenta que en el caso de esta trabajadora, se decide con base en el principio de libertad, que según Nieto (2010) es un "un bien principal en la consolidación del individuo moderno y, por tanto, dentro de un Estado de Derecho." (p.5) por lo que se reconoce que LAIS, debe ser protegida por el Estado al cumplir las características del principio de libertad. Por tanto, de acuerdo a la legislación nacional es legítimo trabajar y practicar la prostitución como una actividad económica.

\footnotetext{
${ }^{1}$ Según el informe presentado por la SDIS "el negocio de la prostitución ha llegado a 19 de las 20 localidades de Bogotá" (p.11), siendo la ciudad una gran receptora de personas que ejercen provenientes de todo el país.

${ }^{2}$ seudónimo asignado en la tutela a la demandante para proteger su identidad.
}

\section{Conclusiones}

El análisis del trabajo sexual, transversal a la configuración de las relaciones de género, ha construido una realidad social en la que se asignan roles diferenciables en el que tanto mujeres como hombres están sujetos a restricciones y mandatos que configuran la corporeidad a sus prácticas y discursos, 
legitimados en el marco jurídico que dan el sentido de realidad a imposiciones sobre el uso "adecuado" del cuerpo.

En este sentido, el control de las funciones de la feminidad y la masculinidad se han apropiado del cuerpo y su expresión. El cuerpo femenino está controlado en sus funciones que en este caso se expresan en el ámbito laboral, estigmatizadas por hacer uso de sus órganos sexuales en la prestación de servicios sexuales remunerados de forma explícita.

De esta forma, el cuerpo en el trabajo sexual es concebido como algo denigrante, por lo que la mujer que lo ejerce es agraviada, desvalorada y marginada por medio de la estigmatización al separarse de la imagen de la mujer "buena" que sigue los mandatos de género y en los marcos jurídicos es puesta dependiendo la perspectiva como víctima o transgresora de la ley, en pocos casos es reconocida su decisión como legitima.

Lo que no se tiene en cuenta en estos discursos es la posibilidad de las mujeres de elegir libremente una opción laboral, haciendo uso para ello de su condición biológica que le permite percibir ingresos con el uso de su cuerpo.

Es necesario replantear los discursos respecto al uso del cuerpo, especialmente aquellos que colocan a la mujer en la condición de víctima sin tener en cuenta su posibilidad de agencia y decisión.

Es necesario dejar atrás una doble moral en la que se sigue mistificando la vagina como el centro sagrado de la feminidad, como aquello que es intocable, entrando en lógicas de dominación que instauran en los cuerpos modos de actuar, pensar o sentir que se despliegan en diversas formas del poder sobre los cuerpos.

\section{REFERENCIAS BIBLIOGRÁFICAS}

Amparán, A. (1998). La teoría de los campos en Pierre Bourdieu. Tomado de: http://www.juridicas.unam.mx/publica/librev/rev/ polis/cont/1998/pr/pr8.pdf

Appiah, K. (2007). La ética de la identidad (1a ed.). Buenos Aires: Latingráfica

Apramp/Fundación de mujeres (2005). La prostitución: Claves básicas para reflexionar sobre un problema. España. Disponible en
http://www.apramp.org/upload/doc8_MAQUETA\% 20APRAMP\%20DEFINITIVA.pdf

Asociación de trabajadoras sexuales "Miluska, V. y D. (2006, April). Trabajo sexual y prostitución desde la perspectiva de las trabajadoras sexuales organizadas. Rostro de Mujer: ¿Trabajo Sexual o prostitución? Tomado de www.cepesju.org/mat_new/boletines_revis/boleti n_rm_portugl.pdf

Aucía, A. (2008). "Trabajo sexual": dificultades en concebir como trabajo aquello que la cultura degrada. Mora (Buenos Aires), 14, 147-151. Tomado de http://www.scielo.org.ar/scielo.php?pid=S1853-0 01X2008000200008\&script=sci_arttext

Barbieri, T. De. (1992). Sobre la categoría género. Una introducción teórico-metodológica. Revista Interamericana de Sociología, 18, 1-19. Tomado de

http://www.identidades.org.mx/attachments/File/ Lecturas/G_nero/05)_debarbieri.pdf

Barreiro, A. (2004). La construcción social del cuerpo en las sociedades contemporáneas. Papers, 127-152. Tomado de http://ddd.uab.es/pub/papers/02102862n73/0210 2862n73p127.pdf

Becker, G., Murphy, K., \& Grossman, M. (2006). El mercado de bienes ilegales: el caso de la droga. journal of political economy, 111(1), 38-60.

Bourdieu (2012). Una invitación a la sociología reflexiva. Argentina: Siglo Veintiuno Editores

Bourdieu, P. (1991). El Sentido Práctico. España: Taurus

Bourdieu, P. (1999). Meditaciones Pascalianas. Barcelona: Anagrama

Bourdieu, P. (2000). La Dominación Masculina. Barcelona: Anagrama

Bourdieu, P. (2004). Cosas Dichas. Editorial Gedisa.

Bourdieu, P. (2009) El sentido práctico. Buenos Aires: Siglo veintiuno editores.

Bourdieu, P.(1997). Razones prácticas sobre la teoría de la acción. Barcelona: Anagrama

Bourdieu, P., \& Teubner, G. (2000). Elementos para una sociología del campo jurídico. En La 
fuerza del derecho. Bogotá: Siglo del hombre editores, Facultad de Derecho de la Universidad de los Andes, Ediciones Uniandes, Instituto Pensar.

Carracedo, Rosario. (2006) Por un análisis feminista de la prostitución. En: Calvo, A. García, M. \& Susinos T. (Coords) Mujeres en la periferia: Algunos debates sobre género y exclusión social. España: Icaria Editorial

\section{Constitución Política de Colombia}

Corte Constitucional de Colombia, sentencia T-620/1995, Magistrado ponente Vladimir Naranjo Mesa, Disponible en www.defensoria.org.co/ojc/sentencias/T-620-95.rt $f(21 / 10 / 2013)$

Corte Constitucional de Colombia, sentencia T-629/2010, Magistrado ponente Juan Carlos Hen a o Pérez, http://www.corteconstitucional.gov.co/relatoria/2 010/t-629-10.htm (21/10/2013)

Daich, D. (2012). ¿ Abolicionismo o reglamentarismo?: Aportes de la antropología feminista para el debate local sobre la prostitución. Runa, (1), 71-84. Tomado de http://www.scielo.org.ar/scielo. php?pid=S1851-9 $6282012000100004 \&$ script=sci_arttext

De Lora, P. (2007). ¿Hacernos los suecos? La prostitución y los límites del Estado. DOXA: Cuadernos de Filosofía del Derecho, 30, 451-470.

Foucault, M. (1975): Vigilar y Castigar. Nacimiento de la prisión. Buenos Aires: Siglo XXI editores.

Foucault, M. (1977): Historia de la Sexualidad, Tomo I (La voluntad de Saber). México: Siglo XXI

Lamas, M. (2003) La marca del género: Trabajo sexual y violencia simbólica. Tesis para optar al título de Licenciatura con grado de Maestría en Etnología. Escuela Nacional de Antropología e Historia. México

Lamas, M. (2007). Algunas reflexiones relativas al derecho a decidir sobre el propio cuerpo. "Género y Cohesión Social" Documento de Trabajo, 1-18. Tomado de http://147.83.15.91/Doc/cols_new/contenidos/dat a/070158100208lamas.pdf

Ministerio de Empleo y Seguridad Social,
Gobierno de España (2007). Evaluación de la ley de regulación de la prostitución. Revista de Actualidad No.101, marzo. pp.80-89. Tomado de: http://www.empleo.gob.es/es/mundo/Revista/

Montoya, V. (2012). ¿Trabajadora sexual o "víctima perfecta"? Límites en el acceso a la justicia. Prisma Jurídico, vol. 11, núm. 1, enero-junio, 2012, pp. 143-161. Universidade Nove de Julho. São Paulo, Brasil

Nettle, P. C. (2005). La regulación de la prostitución en la legislación comparada. Biblioteca del Congreso Nacional de Chile. Tomado de http://www.bcn.cl/bibliodigital/pbcn/estudios/estu dios_pdf_estudios/nro325.pdf

Nieto, J. M. (2010). Trabajo sexual: entre derechos laborales y condenas morales... o el liberalismo en conserva. Comentario sobre la Sentencia T-629 de 2010 de la Corte Constitucional de Colombia. Sexuality Policy Watch. Tomado de http://www.sxpolitics.org/es/?p=1468

Nussbaum, M. (1999). Sex \& Social Justice. Oxford University Press

ONUSIDA. (2009). Nota de orientación del ONUSIDA sobre el VIH y el trabajo sexual. Suiza.

Rubio, Ana (2008) Teoría abolicionista de la prostitución desde una perspectiva feminista. Prostitución y política. En: Holgado, Isabel (ed.). Prostituciones: Diálogos sobre el sexo de pago. Icaria Antrazyt

Sánchez, O. (2011). El cuerpo en Marx, Bourdieu y Foucault. Iberóforum. Revista de Ciencias Sociales de la ..., (11), 121-137. Tomado de http://redalyc.uaemex.mx/src/inicio/ForazarDesca rgaArchivo.jsp?cvRev $=2110 \&$ cvArt $=2110190680$ $07 \&$ nombre $=$ EL CUERPO EN MARX, BOURDIEU Y FOUCAULT

Scott, J. (2000). El género: una categoría útil para el análisis histórico. En M. Lamas (Ed.), El género. La construcción cultural de la diferencia sexual (pp. 265-302). México D.F: PUEG.

Secretaria Confederal para la Igualdad. Departamento Confederal de la Mujer Trabajadora UGT (2005). La prostitución: Una cuestión de género. Tomado de: http://www.ugt.es/Mujer/protitucion_informe2005 _UGT.pdf 
Secretaría Distrital de Integración Social. (2012). Generación de capacidades para el desarrollo de personas en prostitución o habitantes de Calle. Bogotá.
Tirado, M. (2010). Comercio sexual: Una mirada desde la sociología jurídica. Lima: Fundación FEFSA, Instituto Internacional de Derecho y Sociedad-IIDS 